\title{
Green Construction Economy Research Based on LCC Theory
}

\author{
Zhenlin Yan ${ }^{*}$
}

Department of Engineering Economics, Henan College of Finance \& Taxation, Zhengzhou, Henan, 451464, China

\begin{abstract}
LCC theory study on the green construction of economic benefit based on the LCC theory, the concept of full description, a detailed analysis of the existing building economic cost estimation methods, combined with the data, only provides theoretical basis for green construction cost control. Because our country is in the LCC theory and the building materials recycling research is still not perfect, the cost estimation method can correspond to specific project requirements, remains to be demonstrated by practice.
\end{abstract}

Keywords: Economic benefits, green construction, LCC.

\section{INTRODUCTION}

Green construction refers to effective approaches in meaning in architecture life-cycle, to do everything we can to reduce the allocation of resources, without damaging [1] the environment and reduce environmental pollution, and provide humans with a healthy and comfortable living space, which belongs to a building of that and the maintenance of a harmonious relationship between nature. Comparison of green buildings and buildings of the past has many advantages, and their ever-popular, and very much and their relevant green building evaluation system and contains extremely detailed evaluation methods. In the majority of index evaluation system are formed by the designer's point of view, and very few investors. In view of this situation, this paper focuses on the stand cost consultation corner on many aspects and construction of green building evaluation system of science-related research.

LCC (Life Cycle Cost) [2] means "building life-cycle cost" which refers to the building from the planning, design, construction, decoration, used, maintained until the demolition of all costs incurred throughout the process. Contains not only the economic use of capital, as well as environmental and social costs, the costs for various stages of LCC's influence are not the same. LCC theory aims to minimize the total cost of the building project life-cycle, core cost-control is not simply seeking to save construction investment, also based on buildings throughout their life cycle to consider issues from many aspects one by one to achieve cost savings, LCC theory is particularly concerned about buildings in use in completion of the maintenance and operating expenses. Therefore, this paper attempts to use the LCC theory to economic research and analysis of existing buildings.

\footnotetext{
*Address correspondence to this author at the Department of Engineering Economics, Henan College of Finance \& Taxation, Zhengzhou, Henan, 451464, China; Tel: 13598063005; E-mail: yanz11997@126.com
}

\section{DISCUSSION ON THE BENEFITS OF GREEN CONSTRUCTION}

\subsection{The Concept of Green Construction}

Modern of green building has more than simple of building, also including building materials and building way, green building and elevator also exists associated, such as OTIS elevator, OTIS elevator as world leading of Elevator, and escalator, and automatically sidewalk of supplier, has been pursues energy environmental of development concept, constantly promoted in energy environmental field of technology innovation, and will and global synchronization of advanced energy environmental technology with into China, to better to service $\mathrm{Yu}$ China of saving social construction and sustainable development. OTIS elevator's leading research and development of an "elevator" technique, Elevator running in potential energy and kinetic energy can be converted into electricity and fed back into the power grid and provide power for other electrical equipment in buildings, significant savings in electricity, also has made outstanding contributions to green building.

In evaluation process in the, to perfect China of green building evaluation identifies system, established has specifically of green building evaluation identifies Expert Committee to solution evaluation in the encountered of technology problem, and released related technology file, as green building evaluation technology rules added description (planning design part) and green building evaluation technology rules added description (run using part); through held green building evaluation identifies reporter met will, and International Forum on green building assessment and identified by the General Assembly (March 28, 2009) and the green building assessment identifies the Corps (June 24, 2009), the green building assessment identifies the activities carried out extensive publicity and promotion all over the country; China Academy of building [3] research center of Shanghai Branch, the optimization of environmental control to develop green building advisory service identified to assist local governments and green building application identifies the owner. 
Currently evaluation one or two star green building power has decentralization to part provinces, currently has 26 a provinces can himself evaluation a star and II star of green building, Samsung green building needs to live built Department green marked Office and City section will for assessment, currently green building development speed South fast then North, green building development more of provinces has Guangdong, and Jiangsu, and Shanghai, now Beijing and Tianjin development speed compared fast.

Green architecture refers to the architecture of the whole life cycle, the maximum conservation of resources (energy, land, water, and materials), protect the environment and reduce pollution, provide people with healthy, appropriate and efficient use of space, and architecture in harmony with nature.

\subsection{Studies on Green Building-Efficiency Indicators to Quantify}

On quantitative evaluation of many experts take a variety of measures, but only has an independent measurement of the characteristics of the evaluation indicators, but each index use metric measures, there are some differences, comparison of various nature and measurement indicators using measures will have little effect, which led to the final economic evaluation are not comprehensive and rigorous green building. But analytic confirmed the weights [4], using quantitative scoring efficiency indicators measure of green building experts, can effectively address these limitations and achieve economic development and objective evaluation of green building.

In recent years due to social rapid of development speed, so in current formed of one based on green building full life cycle costs in the for evaluation Shi needs reference of indicators very more, main including economic, and social, and interests and technology, multiple aspects of indicators, but this indicators formed of evaluation indicators system, although most main belongs to for green architectural design programmer from technology and function two a aspects carried out science of evaluation, but still can up to green building science of evaluation lay stable of based. Article based on this subject from various angles taking into account features of green buildings have taken two theories, that is, life cycle and the time value of money, two specific economic theories objectively about green building Condition to carry out an objective analysis. Evaluation standard for green building development in China in terms of content consists mainly of 6 technical systems, which focuses on effective and reasonable assessment of residential and public buildings. Based on its energy use and performance systems can be divided into two aspects: materials and use of water resources and land, as well as an outdoor environment, energysaving, water saving and water resource use and energy use, as well as for indoor environmental quality and operations management, it can be known, our evaluation of the project is mainly to protect the environment and conserve resources for evaluating important content.

Building works throughout the cycle is closely related to engineering cost management at all stages. So, be sure to pay attention to construction of cycle control, which means construction preparation phase, construction phase, trial, demoli- tion and renovation stage of systemic management, overall cost for construction and cost must be considered, effectively to make the construction phase and operation and maintenance as a whole. Design, construction units and the owners must unify cost management to ensure effective communication and coordination between the different units.

\subsection{Benefits of Green Building Index Content Analysis}

Environmental green building occupies a very important position in the content, therefore, all of the green building assessment standard in both the indoor and outdoor environment for these two indicators. The meaning can be understood as the environmental impact of green building, from the efficiency point of view, can be understood as contrast and traditional architecture, green architecture in terms of environmental benefits. Mainly refers to the energy saving and operation of engineering cost management and other aspects of saving and, therefore, can also be divided into the economic benefits of green buildings; green building supply service and its role in defining human understanding to provide its people with personal comfort. So, there are 3 main benefits of green building index [5], can generally be summarized for personal comfort, economic as well as environmental benefits, which plays an irreplaceable role in the economic evaluation of green building, any one may not lack.

According to related research can show that same project, green building methods and compared to traditional building methods, green building is much higher than the cost of traditional architecture in the initial period, but its cost is lower than the cost of traditional architecture at run time. So, you must take into account life-cycle cost theory under the condition of green building cost index can be settings related to the activities carried out. Life cycle costs are by definition mainly refers to the stage of construction began during the life of a one-time cost and construction demands of operating and maintenance cost of funds, resulting in life-cycle cost more cumbersome and variety. Because buildings can usually survive for a long time, in order to ensure that the total life-cycle costs can be calculated correctly, the staff must be taken in computing to scientific theories of the time value of money calculations.

Establishing and perfecting the management system of the construction site, and allows smooth construction cost management and co-ordination between different sectors and departments should also clearly, effectively limiting the owners ' behavior in order to adapt to the development of the market economy situation. Upgrade cost consulting management, policies and regulations should be established accordingly, building on their obligations and responsibilities of the institutions has improved. In addition, the contract management skills improve the rule of law and contract management, promotion of rule of law of contract, scientific and rationalized cost management of construction projects and project duration.

Bid if you want accurate and reasonable, to be able to lay a solid foundation for construction projects, smooth and inviting, taking the bidding too high or too low will adversely effect on the cost management of construction projects. Therefore, bid construction projects must carry out the necessary management. Which need to be strengthened in sev- 
eral ways, to be installed in a detailed survey, second in the tender documents and detailed study of its tender system? Thus scientific, perfect quote management system to establish a sound, so bid management rationalization moving toward unceasingly, and will also be helpful in the proper cost management in construction engineering.

Control project cost management processes on one hand is the most important part, on the other hand also has the ability to project to determine its profitability. Especially in today's fiercely competitive market conditions [6], in terms of cost of the project are gradually reduced, cost control has increased as the top priority. So, to quality control over the construction, technical and economic integration must be, and need to strengthen quality and time management.

Present value (PV) refers to the case of taking into account the time value of money and the present value of an amount of money in the future. Net present value is within the whole period of the project the rate at which cash flows as required, converted to the commencement of the project, the cumulative discounted cash flow value, net present value analysis. Can be calculated according to the following formula:

$N P V=\sum_{t=0}^{n}\left(B_{t}-C_{t}\right)\left(1+i_{c}\right)^{-1}$

Net annual value is obtained in the project is initially based on the net present value basis of capital recovery factor converted to equivalent annual value. Can be calculated by the following formula:

$$
N A V=\left[\sum_{t=0}^{n}\left(B_{t}-C_{t}\right)\left(1+i_{t}\right)^{-1}\right] \frac{i_{c}\left(1+i_{c}\right)^{n}}{\left(1+i_{c}\right)^{n}-1}
$$

\subsection{Problems in the Existing Building}

Nonstandard design: Design sector in the pursuit of economic interests, battling for the design project, and also because of its time, a lower effect in product design, inferior product quality formed, lack of complete, detailed, and contradictions that exist more, lack of reasonable calculation of the quantities in the appropriate way.

Installation and construction team is weak: As head of the construction and installation process, most of them migrant workers, lack of professional knowledge, directly affect the overall technical strength and construction team, due to low prices for most of the construction unit in the form of bid, prompting the settlement buck are frequent. For the construction phase, will produce construction records are not complete, the construction drawings are not complete, the construction of such phenomena as hidden item cannot be checked in a timely manner, this series of questions will make the actual consumption is very difficult to verify, and in turn cannot make an accurate reflection of project cost and other issues.

Construction products price false: Because information is not accurate, construction and installation products price survey of market conditions cannot be presented, directly affect the project cost. More invoice purchasing management more lax, discretion, does not reflect the real price of the product. Confirmation and invoices are approved is very difficult, this work will not only cause disputes, will have a greater workload, invoices for purchases made in accordance with the settlement, nor to control engineering cost. If the use of cheap, poor quality of products, will generate considerable profits, but construction and installation reliability will be greatly reduced.

Quotas incomplete: Now, highlighted inadequate quota in construction projects, therefore are not able to meet the needs of building decoration industry. Embodiment without a full range of fixed items, loopholes will make some construction enterprises using illegal means. In addition, a quota does not perform well, because lack of experience in the building during the construction process, and its asking price. And, mainly responsible for the quality of the staff in the project budgets with poor quality, not to seriously comply with the relevant provisions in the project cost or shall prevail. First, the project budget is not accurate, more items missing and, secondly, not to be able to project cost control and a severe risk computation and overestimate. If so, funds will not be able to have a greater investment, construction and installation the project will present a lower billing accuracy.

\section{LCC SIX STAGES OF CONSTRUCTION COST MANAGEMENT}

Construction project can be divided into investment decision-making, design, tendering, construction, use and maintenance, refurbishment and demolition phases in six stages, LCC cost management can be introduced into these six stages.

\subsection{Decision Period Management}

Decision-making stage is to demonstrate the investment construction projects, addressing the issue of investment processes, building construction, demolition and rebuilding programmers in economic, environmental and social aspects such as efficiency maximization principle, from which to choose the best option, while issues of feasibility, necessity to demonstrate. LCC manage the stresses of construction cost [7], fully integrated project overall benefit costs, including economic costs essential for environmental cost and social cost savings, so building projects investment decision phase, should consider not only the economic dimension, also need to integrate sustainable development concepts which were infiltrated by management decision-making process.

\subsection{The Design Phase Management}

Existing buildings are different from general building projects, will also be responsible for identification and detection of building at the design stage work, to develop programmers based on test results and begin to design. Engineering cost control in design stage of the building is also an important stage in materials selection, energy conservation and environmental protection should be the premise, give full play to resource advantages play out around the construction site, further improve land utilization, and control the impact of construction on the environment. Finally, the solution requires a combination of theories of LCC, building 
function and cost optimization, efficient use of capital. Problems in the construction process, we must take into account the energy consumption, as shown in Fig. (1) is the energy consumption over the past decade the demand curve.

\subsection{Bidding Management}

LCC theory to bidding phase accuracy emphasized rationality and the preparation of the tender documents. In existing buildings, should take the form of general contract, because the General Contracting mode of unified management and planning purposes, allowing management to the whole course of construction procurement, technology and process optimization, which is critical to grasp and realize the economic benefits of the duration of.

\subsection{Construction Phase}

Existing buildings construction stage is very important, it is the intention of the design into construction site, if it is a renovation of the existing buildings is required during the construction phase focuses on facilities and environmental protection, actively choose energy-saving technologies [8], and improve resource utilization. Also needs to be considered in the construction process is the problem of air quality, air quality and the price is proportional to the, as shown in Fig. (2).

\subsection{Maintenance and Operation Phase}

Effect of investment in maintenance and operation phase is played and stages of recovery fund management, property management services at this stage must be optimized to replace energy-intensive facilities, green energy-saving products. Maintenance and operation costs to test project decisions, design work was successful, according to the LCC theory in decision-making, the design phase of the project will need to take into account the cost of building put into use, practice will complete operational measures, so that quality maintenance services with building life-cycle process.

\subsection{Renovation or Demolition Phases}

Renovation or demolition phase, cost comes mainly from the equipment leasing, manpower, materials, construction waste disposal recycling and so on. Sustainable development based on construction projects, it should be recycled after demolition and building materials such as wood, metal, structural components of recovery, which requires building selection a little more environmentally-friendly energysaving materials in the design stage, in order to reduce the cost of renovation demolition.

\section{GREEN CONSTRUCTION COST ESTIMATION BASED ON LCC THEORY}

In accordance with the relevant provisions of our current project cost, construction costs include construction from design to completion; various costs incurred costs, such as construction, preparation of funds, construction loans, and so on. To make existing buildings play a maximum value, preliminary cost estimates are particularly important; cost estimating methodologies currently applied to existing buildings include the following.

\subsection{Partial Estimation Method}

When the itemized estimating method is adopted, according to building size, construction of the project, project costs and life-cycle costs [9], analyzing the cost of each sub-item, drawing on relevant costing standard, calculate the costs involved of the project one by one, finally together, draw investment estimates.

\subsection{Index Estimation Method}

Application index estimation method, requires local administrative departments prepare all kinds of investment estimation index, will come before the estimate multiplied by the area and volume of investment, reach the heating, lighting, drainage and other project specific costs and reserve funds and other capital cost estimates, construction cost estimate final phase could be drawn.

A total life cycle cost of the project is through the present value of the cost of each together, splitting and minus the residual value. Simple generic formula is as follows:

$$
L C C_{p v}=I_{0}+\sum_{t=1}^{T} \frac{I_{t}+M_{t}+E_{t}}{(1+i)^{t}}
$$

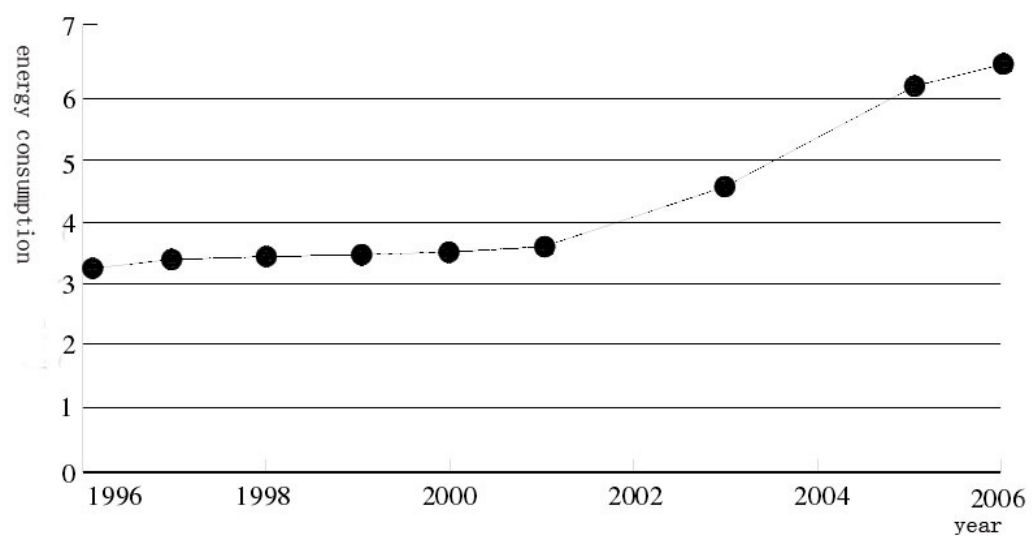

Fig. (1). Energy consumption over the past decade. 


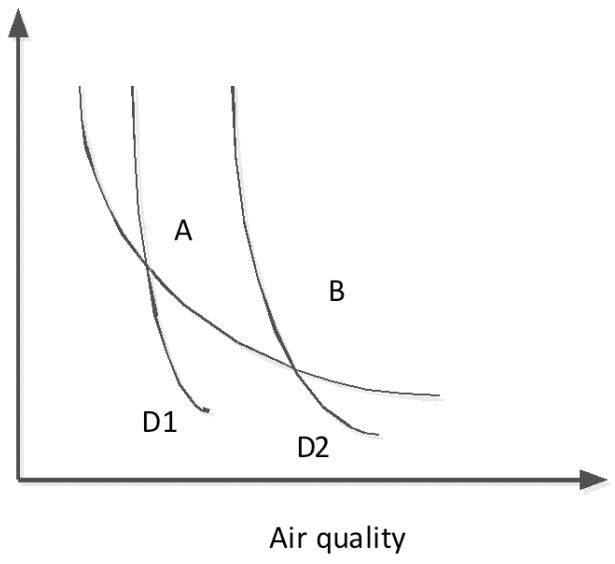

Fig. (2). Air quality and the price proportional.

\subsection{Repair Cost Estimates}

Pursuant to China property management regulations provides, owners needs according to national related provides paid property special maintenance funds, because special maintenance costs by involving of maintenance range than larger, so hard in transformation maintenance problem appeared only began charged, so property sector must ahead of two owners charged this pen costs and property management maintenance costs standard is according to China different area situation to developed of, each province, and city, and autonomous regions, and municipalities economic conditions and human costs are has without [10], So maintenance costs are currently mainly real estate sales unit to collect, the overall costs generally below value of housing $5 \%$.

\subsection{Property Management Cost Estimate}

Property management regulations on property costs has clear provides: all owners through selection of way to decided property company, owners and property company signed service contract, commissioned property company on housing building and supporting facilities, and site, for maintenance, and management and maintenance, and is responsible for life regional within of sanitation, and security, work, achieved these service by needs of funds, and human costs, and management costs by owners bear, is paid corresponding of property service costs. Building property management cost estimates are usually used in two ways, first issued under local pricing departments estimate the standard, if there is no corresponding price control Department, by property companies on the basis of "property management cost method" to estimate. Operation management and maintenance of green building occupies most of the time and money throughout the building life cycle, as shown in Fig. (3).

\subsection{Estimate of Construction Cost}

LCC for housing use in the theory of costs involved in content-heavy, it is difficult to estimate, which include electricity, heating, gas, air conditioning costs, energy costs, plus other expenses such as cable television, water and communications [11]. Abroad at the time of collecting the fees, is generally based on the relative cost estimate data to select the corresponding energy consumption index, if the residential unit energy consumption calculation according to tons of standard-used, is based on an energy consumption index, multiplied by the living area, adjusted for the actual situation, and finally obtained the corresponding energy consumption costs.

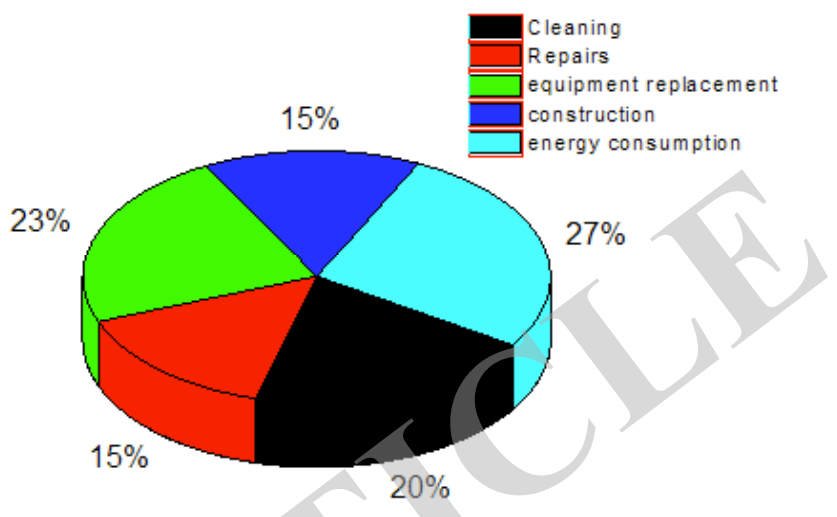

Fig. (3). In the process of building costs.

\section{CONCLUSION}

Current in our country in both building economic aspects of research also needs to be $\mathrm{Yu}$ perfect, which needs concern of problem main contains following what time: first, perfect related planning, and design policy, and legal regulations and technology standard, ensure in on both building for design Shi can has according to; second, established both building economic evaluation indicators system and evaluation standard, let both building decision and design can has judge according to; third, perfect both building of transformation policy and the related specification standard, in material of select Shang provides guide direction And easy to refit existing buildings, demolition, recycling work smoothly. LCC standard we can use to improve the economic benefits, while also taking into account environmental considerations.

\section{CONFLICT OF INTEREST}

The author confirms that this article content has no conflict of interest.

\section{ACKNOWLEDGEMENTS}

This work is supported by the Soft Science Research Plan Project of Henan Province, China (No.142400411029), the Soft Science fund of the Science and Technology Department of Henan, China.

\section{REFERENCES}

[1] D. Castro-Lacouture, J. A. Sefairb, L. Flórez, and A. L. Magalia, "Optimization model for the selection of materials using a LEEDbased green building rating system in Colombia," Building and Environment, vol. 44, no. 6, pp. 1162-1170, 2009.

[2] R. Flanagan, Life Cycle for Constructing (LCC), Surveyors Publication, London, 2011.

[3] U.S. Green Building Council: LEED 2009 New Construction for Member Ballot, 2009.

[4] N. Banaitiene, A. Banaitis, A. Kaklauskas, and E.K. Zavadskas, "Evaluating the life cycle of a building: Amultivariant and multiple 
criteria approach," The International Journal of Management Science, vol. 36, no. 3. pp. 429-441, 2008.

[5] "Life Cycle Cost Analysis Guidelines 2002[C]" American Department of natural Resources Energy Bureau, US 2012.

[6] Q. Hu, "Green building energy saving review," Research and utilization of energy, vol. 6, no. 2, pp, 122-130, 2012.

[7] W. L. Paul, and P. A. Taylor, "A comparison of occupant comfort and satisfaction between a green building and a conventional building," Building and Environment, vol.43, no.1l, pp.1858-1870, 2008.
[8] O. Orshan, "Life Cycle cost: a tool for comparing building alternative," In: Proceeding Symposium on Quality and Cost in Building. 2012, 1 .

[9] D. Gottfried, and H. Malik, Perspectives on green building, Renewable Energy Focus, vol. 3, no.6, pp.38-41, 2009.

[10] C. Xia, Y. Zhu, and B. Lin, "Renewable energy utilization evaluation method in green buildings," Renewable Energy, vol. 33,no. 5, 2011.

[11] M. Xiaofeng, "Benefits of green offices in the UK: analysis example built in the 1990," Sustainable Development, vol. 14, no. 3, 2006.

(C) Zhenlin Yan; Licensee Bentham Open.

This is an open access article licensed under the terms of the (https://creativecommons.org/licenses/by/4.0/legalcode), which permits unrestricted, noncommercial use, distribution and reproduction in any medium, provided the work is properly cited. 